\title{
SEROLOGICAL SYPHILIS CONTROL IN PREGNANCY
}

\author{
BY \\ OLAV IDSøE and T. M. VOGELSANG \\ From the V.D. Department, Bergen Public Health Service, and Gade's Institute, \\ University of Bergen, Norway
}

Bergen is a typical sea port on the west coast of Norway with a population of about 116,000 . Many of the country's exports and imports pass through the town, and there is a lively exchange of seamen sailing to and from foreign ports. For this reason, from the epidemiological point of view, Bergen experiences to a certain extent the fluctuations in the incidence of the venereal diseases abroad.

Syphilis in Bergen during and after World War $I$. -During and after World War I, there was a marked rise in the number of cases of acquired syphilis. The peak was reached in 1920 with 259 cases ( $28 \cdot 5$ per 10,000 inhabitants). It was characteristic of the brisk shipping traffic at that time that there were 200 male and 59 female patients. During the same period there was also a series of cases of congenital syphilis. Accordingly, in 1919, a home for children with congenital syphilis (a Welander Home) was provided with accommodation for 20 children from infancy to school age. However, the 1930s witnessed a gradual and considerable decline in the number of notified new cases of acquired syphilis. Congenital syphilis became at the same time so rare that the Welander Home came to be regarded as superfluous, and was closed down in 1940.

Syphilis in Bergen during and after World War II. -With the German occupation of Bergen in 1940, most of the town's shipping moved to Allied ports, sailing abroad for the rest of the War. Hitherto most of the new early cases of syphilis had been men, particularly seamen who had returned home from abroad, but now, communications with the outer world being broken, there was a change in this respect. The German occupation led to a marked rise in the number of cases of syphilis from 1942 onwards. We do not know how many cases there were among the German occupation forces nor among the armies of liberation after Norway was set free, but we do know that this rise was most marked among the women of Bergen (see Table I). Thus in 1943 there were 90 new notifications of women and 51 of men. While 80 per cent. of the 1,039 cases of acquired syphilis notified in the 5-year period 1916-20 were males, 60 per cent. of the 563 cases notified in the 5-year period 1942-46 were females. In the 5-year period 1936-40 the notified cases of syphilis in women numbered 44, whereas in the 5-year period 1944-48 the corresponding figure was 331 .

Precautions Taken to Prevent Prenatal Syphilis.On account of this considerable rise in the number of notifications of acquired syphilis, particularly in women, a simultaneous rise in the number of cases of congenital syphilis was to be feared. In January, 1944, as a step in the campaign to prevent

TABLE I

NOTIFIED CASES OF EARLY SYPHIIIS IN BERGEN, 1936-1948

\begin{tabular}{rrr|r|r|r|r|r|r|r|r|r|r|r|r|r}
\hline \multicolumn{3}{r|}{ Year } & 1936 & 1937 & 1938 & 1939 & 1940 & 1941 & 1942 & 1943 & 1944 & 1945 & 1946 & 1947 & 1948 \\
\hline Male &.. &.. & 19 & 14 & 13 & 16 & 17 & 6 & 25 & 51 & 40 & 31 & 73 & 68 & 66 \\
Female &.. &.. & 9 & 9 & 14 & 7 & 5 & 2 & 26 & 90 & 69 & 85 & 73 & 52 & 52 \\
\hline \multicolumn{1}{rl}{ Total } &.. &.. & 28 & 23 & 27 & 23 & 22 & 8 & 51 & 141 & 109 & 116 & 146 & 120 & 118 \\
\hline
\end{tabular}


TABLE II

CHIIDBIRTHS AND SEROLOGICAL CONTROL TESTS IN BERGEN, 1944-1948

\begin{tabular}{c|c|c|c}
\hline Year & $\begin{array}{c}\text { Number of Childbirths } \\
\text { in Bergen }\end{array}$ & $\begin{array}{c}\text { Number of Serological } \\
\text { Control Tests }\end{array}$ & $\begin{array}{c}\text { Number of Childbirths } \\
\text { in the State } \\
\text { Maternity Hospital, Bergen }\end{array}$ \\
\hline 1944 & 1,944 & 860 & \\
\hline 1945 & 2,028 & 771 & 1,650 \\
\hline 1946 & 2,460 & 1,367 & 1,488 \\
\hline 1947 & 2,201 & 975 & 1,418 \\
\hline 1948 & 2,014 & 988 & \\
\hline & 10,647 & 4,961 & \\
\hline
\end{tabular}

this process, the Bergen Public Health Service requested the doctors, midwives, and control stations for expectant mothers to send in specimens of blood from pregnant women in order that they might be systematically examined for syphilis by serological tests. Since February 1, 1944, these serological tests for syphilis have been carried out at Gade's Institute, and the results of these tests during the period 1944-48 are discussed below.

\section{Material and Methods}

Table II shows the number of confinements of women domiciled in Bergen in the 5-year period 1944-48, and how many women underwent serological tests in the course of their pregnancies. It will be seen that there were altogether 10,647 confinements, whereas the serological control of pregnancy was carried out on only 4,961 pregnant women, i.e. on barely half. However, it has become more and more usual in Bergen for women to be confined in maternity hospitals ; and in this 5-year period only 647 of all the confinements took place at home. Most of them took place at the State Maternity Hospital in Bergen or at the Municipal Maternity Hospital. The latter hospital participated from the outset in the serological control of these cases, hence the investigations recorded in this study and the results referred to concern those women confined at the Municipal Maternity Hospital. At the State Maternity Hospital the practice has been adopted since the beginning of 1946 of applying serological tests for syphilis to the confined women if they had not been thus examined in the course of their pregnancies. Since 1946, practically all the women confined in Bergen have thus been kept under serological control either during their pregnancies or at the time of confinement.

Most of the specimens of blood from the State
Maternity Hospital in Bergen were examined at another laboratory, but all the serological tests carried out during pregnancy and on women confined at other maternity hospitals were undertaken at Gade's Institute. All the specimens of blood were examined by the Wassermann reaction, Kahn's standard reaction, and Meinicke's clarification test. In addition other flocculation reactions have also been employed from time to time. Since 1946 we have employed cardiolipin-lecithin-cholesterol antigens in addition to crude antigens in carrying out Wassermann's reaction. The specimens were handled, and the results communicated to the doctors by the Venereal Disease Department of the Bergen Public Health Service, which saw that doubtful specimens were revised and that pregnant women found to be syphilitic were given specific treatment either by the Public Health Service or by doctors in private practice. Before 1946 the standard neosalvarsan-bismuth treatment was given. After 1946, when penicillin became available, most of the patients were treated with it, in a few cases in combination with arsenic and bismuth (As-Bi). The babies were examined directly after birth and thereafter at 2, 4, 6, 9, and 12 months. After this age an attempt has been made to carry out yearly examinations, both clinical and serological, for at least three years.

The present report does not deal with women already under treatment and supervision for early syphilis, who had been found to be syphilitic in some other way and had meanwhile become pregnant. Incidentally, it is not such women who transmit their syphilis to the foetus, but the undetected cases of syphilis, usually latent, which present the real danger during pregnancy; it is these undetected cases which mass examinations are designed to disclose. 


\section{Results}

Among the 4,961 specimens, 4,850 gave negative reactions to all the tests. Three women giving negative reactions were infected with syphilis later on in their pregnancies and then gave strong positive reactions.

In 71 cases (1.4 per cent. of specimens examined) the verdict was doubtful at the first examination. Included in this figure were all the specimens giving the slightest positive reaction, even if this was so in only a single test. Thus, for example, when only one test gave an uncertain result and the other tests were negative, the result in toto was recorded as doubtful. The fact that 1.5 per cent. of the specimens showed an uncertain result at the first examination may be largely due to several specimens having been received in an unsatisfactory condition. In the greater part of the period under review the specimens sent in by the Bergen Municipal Hospital were derived from blood from the umbilical cord. These were often very haemolytic and to some extent decomposed when they reached us, but were tested all the same.

On further control tests, three of the 71 women gave concordant positive reactions and were found on clinical examination to be infected with syphilis. Among the forty specimens giving positive serological reactions at the first examination were two found to be false positive. Altogether, these tests showed 44 women to be syphilitic (i.e. 8.9 per thousand).

A. Relationship between Primiparae and Pluriparae and the Stage of Pregnancy at the Time of the Serological Control Investigations.-Among the 4,961 specimens examined were 1,867 (fully onethird of the total) taken from primiparae ; among the 44 women found to be syphilitic there were 36 primiparae (four-fifths of the total). Space was provided for recording the date of the last menstruation in the form sent with the specimens of blood by the Bergen Public Health Service for serological tests for syphilis. As this space was filled in by most of the doctors concerned, we have been able to show in Table III at what stage in pregnancy the first specimens were tested. In 3,048 cases
(60 per cent.) the specimens were taken within the first six months of pregnancy, and in 1,478 cases (30 per cent.) after the sixth month of pregnancy. In 435 cases (10 per cent.) no mention was made of the stage in pregnancy at which the specimen was taken.

B. Negative Results Changing Later to Positive Results.-In three cases the tests gave negative results at first whereas all the subsequent tests were positive.

(a).-The first of these, an unmarried woman aged 23, gave negative reactions when examined serologically for the first time in the third month of pregnancy. In the seventh month of pregnancy she consulted the Venereal Disease Department because of ulcers on the genitals, and the serological reactions were then markedly positive. She was given specific treatment and gave birth to a healthy infant.

(b) and (c).-The other two cases were married primiparae, aged 30, who gave negative reactions when first examined in the fifth month of pregnancy. When one was re-examined in the seventh month, she presented a syphilitic rash which tallied with markedly positive reactions. She was given specific treatment and gave birth to a healthy infant. The other woman gave birth to a girl with signs of syphilis, and both mother and infant gave positive serological reactions. The infant became clinically and serologically symptom-free after specific treatment. The husbands, both seamen, were summoned to present themselves for examination by the Venereal Disease Department; both were found to be suffering from early, untreated syphilis and they had infected their wives just after the first, negative examination.

C. Doubtful Results Changing Later to Positive Results.-In three cases in which the first examinations showed doubtful results, all the subsequent examinations proved to be positive, and the three women were found to be infected with syphilis.

(a).-Thefirst was a 4-para who gave a doubtful reaction in the sixth month of pregnancy; on being re-examined three weeks later, her reactions were markedly positive. Her three older children were serologically negative, but her husband gave positive reactions.

(b).-The second was a primipara who gave doubtful reactions at the time of her confinement. On further

TABLE III

STAGE IN PREGNANCY AT THE TIME OF THE SEROLOGICAL CONTROL TESTS

\begin{tabular}{ll|c|c|c|c|c}
\hline & $\begin{array}{c}\text { Within } \\
3 \text { Months }\end{array}$ & $\begin{array}{c}\text { Within } \\
6 \text { Months }\end{array}$ & $\begin{array}{c}\text { After } \\
6 \text { Months }\end{array}$ & $\begin{array}{c}\text { Time not } \\
\text { indicated }\end{array}$ & Total \\
\hline Number of Pregnant Women Tested &.. & 1,853 & 1,195 & 1,478 & 435 & 4,961 \\
\hline
\end{tabular}


tests the reactions increased in strength, and after a month all were positive. The infant was serologically negative at birth and 6 months later. The husband, however, who was not given specific treatment, was serologically positive, and had probably infected his wife just before her confinement.

(c).-The third was a pluripara, whose infant was stillborn. Only the Wassermann reaction was faintly positive. She could not be re-examined until six months later, and her serological reactions were then positive. It was found that she and her husband had been given very inadequate treatment for syphilis three years earlier. Her three older children, the youngest 4 years old, were examined and all found to be serologically negative.

D. Doubtful Results Changing Later to Negative Results.-Specimens taken for serological examination from 68 women either during pregnancy or at the time of confinement at first showed doubtful results, and at subsequent examinations gave negative results. As already pointed out, several of these specimens were taken from blood from the umbilical cord. When specimens of blood were subsequently taken in the usual way the results were negative. In most of these cases the first control test already showed negative results, but in a few some particular test might remain positive on several occasions and then turn negative as in the following example.

A married primipara, aged 26 , was in the fourth month of pregnancy. The first two Wassermann reactions were markedly positive, whereas the flocculation reactions were negative. They were negative also at the third examination when the Wassermann reaction had diminished in strength and a $T$. pallida reaction, carried out at the same time, was negative. A specimen of blood from the husband gave negative reactions. On further examination the Wassermann reaction also became negative.

E. False Positive Results.-The serological reactions were at first positive but on further testing negative in two cases.

(a).-A married primipara, aged 22, was in the sixth month of pregnancy when her first serological examination showed positive Wassermann and Meinicke reactions. The other reactions could not be carried out for want of sufficient serum. When she was re-examined ten days later, the Meinicke reaction was still positive, but the Wassermann reaction was negative. Seven days later all the reactions were negative. She was confined at term of a healthy infant.

(b).-A 3-para, aged 28, gave positive reactions to all the tests (Wassermann with crude and with cardiolipin antigen, Kahn, Meinicke, and V.D.R.L. macro) at the first serological examination made in the fifth month of pregnancy. But control tests carried out eight and 12 days later were both entirely negative. She gave birth to a healthy infant. It transpired that she was suffering from an attack of acute bronchitis of a week's duration when the first specimen was tested, which may perhaps explain the false positive reactions.

F. Positive Results.-The serological examination for syphilis in pregnancy followed by later examinations led to the discovery of syphilis in 44 women who were given specific treatment as soon as the diagnosis was certain. Table IV gives a survey of these cases and the results of the treatment.

Four women had received treatment for syphilis before they became pregnant, but had eluded supervision until they were examined during their pregnancies. The remaining forty cases were new ones, and among them were 36 primiparae. As many as 26 were found to be syphilitic before or during the sixth month of pregnancy, nine were thus discovered between the seventh and the ninth months of pregnancy, and nine at the time of confinement. Specific treatment was given to 31 during their pregnancies. In four cases it was impossible to give specific treatment on account of the special conditions existing during the German occupation, and nine women were given specific treatment after their confinements.

The 31 women who were given specific treatment during their pregnancies gave birth to thirty healthy infants, seven of whom gave positive serological reactions at birth. Three, whose mothers had begun specific treatment before the seventh month of pregnancy, turned serologically negative without being treated after birth, but with the other four, whose mothers had begun specific treatment in the eighth to the ninth months of pregnancy it was found advisable to give treatment until the serological tests became negative. One woman, who received quite irregular and inadequate treatment after the seventh month of pregnancy, was confined of a stillborn infant. The four who did not receive specific treatment, aborted or were confined of stillborn infants.

Among the nine women in whom syphilis was not discovered until the time of their confinement, one gave birth to a healthy child. This woman was presumably infected just before she was confined (see case $(b)$ under C).

Four infants were born with signs of congenital syphilis and presented positive serological reactions. Under specific treatment they became well, and their serological reactions became negative. Thus the final result in the nine cases where syphilis was not discovered till the mothers were confined was five healthy infants and four stillborn. The final result for the 44 cases of syphilis was 36 healthy infants, six stillborn, and three abortions.

G. Control of Pluriparae.-Many doctors who had sent in specimens of blood from primiparae, 
and who had learnt that the reactions were negative, were inclined to think that when these women again became pregnant it was superfluous to send in new specimens for examination. This argument has been common particularly when the women were married. But in our material there are several examples of married pluriparae becoming infected with syphilis. Two such cases have already been mentioned ( $(a)$ and $(c)$ under $C)$. A third such case is the following :

A married woman, aged 21, gave birth to her second infant at term. It was fully developed and was breastfed, thriving well at first. When it was $2 \frac{1}{2}$ months old, a rash appeared which gradually became desquamating. The infant began to flag at the breast, and to suffer from coryza and a slight cough. A large spleen was palpable, and the liver was much enlarged. Specimens of blood from both mother and infant gave markedly positive syphilis reactions. The infant died when three months old of congenital syphilis. A year earlier, the mother had given birth to her first child, and while she was pregnant with this child, her blood had been tested with negative results. When she became pregnant for the second time and presented herself for a medical examination, her doctor considered it unnecessary to take a new specimen of blood.

\section{Discussion}

About half the total number of 10,647 women confined in Bergen in the 5-year period 1944-48 underwent serological tests for syphilis during their pregnancies. Practically all the remainder were thus examined when confined, as nearly all of them were confined in maternity hospitals. Yet only nine of the 44 women found to be syphilitic were not detected until the time of confinement. Thus it was in the course of examinations carried out during pregnancy that most of these cases were unearthed.

As many as 36 of the 44 syphilitic women were primiparae. This suggests that it is first and foremost the primiparae whom we should try to deal with in such an investigation as this. In the 5-year

TABLE IV

POSITIVE RESULTS OF THE SEROLOGICAL EXAMINATIONS

\begin{tabular}{|c|c|c|c|c|c|c|c|c|c|c|c|c|}
\hline \multirow{4}{*}{ Year } & \multirow{4}{*}{$\begin{array}{l}\text { Total } \\
\text { No. of } \\
\text { Mothers } \\
\text { positive }\end{array}$} & \multicolumn{11}{|c|}{ Stage of Pregnancy at which Positive Result was Obtained } \\
\hline & & \multicolumn{4}{|c|}{ First 6 months of pregnancy } & \multicolumn{4}{|c|}{7 th-9th month of pregnancy } & \multicolumn{3}{|c|}{ Post Partum } \\
\hline & & \multirow[b]{2}{*}{ No. } & \multicolumn{2}{|c|}{ When treated } & \multirow[b]{2}{*}{ Infants } & \multirow[b]{2}{*}{ No. } & \multicolumn{2}{|c|}{ When treated } & \multirow[b]{2}{*}{ Infants } & \multirow[b]{2}{*}{ No. } & \multirow[b]{2}{*}{$\begin{array}{c}\text { Treated } \\
\text { earlier }\end{array}$} & \multirow[b]{2}{*}{ Infants } \\
\hline & & & Earlier & $\begin{array}{c}\text { During } \\
\text { preg- } \\
\text { nancy }\end{array}$ & & & Earlier & \begin{tabular}{|c|} 
During \\
preg- \\
nancy
\end{tabular} & & & & \\
\hline 1944 & 10 & 8 & 1 & 7 & $\begin{array}{c}7 \mathrm{R}- \\
1 \mathrm{R}+ \\
\mathrm{R}-\end{array}$ & 2 & 0 & 1 & $\begin{array}{l}1 \mathrm{R}- \\
1 \text { stillborn }\end{array}$ & & & \\
\hline 1945 & 6 & 4 & 0 & 4 & $\begin{array}{l}3 \mathrm{R}- \\
1 \text { abort. }\end{array}$ & & & & & 2 & 0 & $\begin{array}{l}1 \text { L.c. } \\
1 \text { stillborn }\end{array}$ \\
\hline 1946 & 12 & 7 & 1 & 6 & $\begin{array}{l}6 \mathrm{R}- \\
1 \text { abort. }\end{array}$ & 2 & 0 & 2 & $\begin{array}{r}2 \mathrm{R}+ \\
\mathrm{R}-\end{array}$ & 3 & 1 & $\begin{array}{l}1 \mathrm{R}- \\
2 \text { stillborn }\end{array}$ \\
\hline 1947 & 8 & 3 & 0 & 3 & $3 \mathrm{R}-$ & 4 & 1 & $\frac{3}{1 \text { irreg. }}$ & $\begin{array}{l}1 \mathrm{R}- \\
2 \mathrm{R}+ \\
\mathrm{R}- \\
1 \text { stillborn }\end{array}$ & 1 & 0 & 1 stillborn \\
\hline$\overline{1948}$ & 8 & 4 & 0 & 3 & $\begin{array}{l}3 \mathrm{R}- \\
1 \text { abort. }\end{array}$ & 1 & 0 & 1 & $1 \underset{\mathrm{R}}{\mathrm{R}+}$ & 3 & 0 & $\begin{array}{l}3 \text { L.c. } \\
\mathrm{R}-\end{array}$ \\
\hline \multirow[t]{2}{*}{$\begin{array}{c}\text { Total } \\
5 \text { years } \\
1944 \\
48\end{array}$} & 44 & 26 & 2 & 23 & $\begin{array}{c}22 \mathrm{R}- \\
1 \mathrm{R}+ \\
\mathrm{R}- \\
3 \text { abort. }\end{array}$ & 9 & 1 & 8 & $\begin{array}{l}2 \mathrm{R}- \\
5 \mathrm{R}+ \\
\mathrm{R}- \\
2 \text { stillborn }\end{array}$ & 9 & 1 & $\begin{array}{l}1 \mathrm{R}- \\
4 \text { L.c. } \\
4 \text { stillborn }\end{array}$ \\
\hline & \multicolumn{12}{|c|}{$\begin{array}{l}\mathbf{R}-=\text { Serological syphilis reactions negative. } \\
\left.\mathbf{R}+{ }_{\mathbf{R}}\right\}=\text { Reactions positive, later negative. } \\
\text { L.c. }=\text { Lues congenita. }\end{array}$} \\
\hline
\end{tabular}


period under review there were altogether 4,333 primiparae, 1,867 of whom were examined during their pregnancies. In other words, about two-fifths of all the primiparae were examined during their pregnancies. In planning and carrying out such investigations we ought to attach the greatest importance to examining primiparae. However, as already pointed out, our material contains several examples of married women becoming infected with syphilis after their first confinements. The serological control of syphilis should therefore be repeated at every new pregnancy.

It should be noted that 60 per cent. of the specimens were examined before the seventh month of pregnancy, and 60 per cent. of the positive results were obtained during this interval. It is probable that if pregnant women could be examined as early as possible in their pregnancies we should discover most of those infected with syphilis. An examination early in pregnancy does not, however, give us an absolute guarantee with regard to this problem, for even among our own examples three women, who were originally serologically negative, and three others who showed doubtful reactions, were found to have been infected with syphilis late in pregnancy, five of them by their husbands. As a rule it will in practice be impossible to undertake several examinations during one and the same pregnancy, yet we can do much to make good this omission by repeating serological tests for syphilis at the time of the mother's confinement, and this is now being done in Bergen.

In three of the 71 cases in which the serological findings were doubtful, further tests yielded positive reactions, while in two cases in which reactions had at first been positive the women concerned proved not to be syphilitic. It is therefore necessary to repeat tests when the results are doubtful. Also we must not start anti-syphilitic treatment only on the basis of a single positive serological test when there is no other sign of syphilis.

Even when we take these precautions, it sometimes happens one test or another leaves some doubt as to the presence of syphilis. This is particularly the case when a doubtful result is repeated on renewed testing, and here we are confronted with a difficult problem. Were it not for the pregnancy, we should in such cases advise a policy of wait-and-see and repeat the testing after an interval of a couple of months. But in a case of pregnancy the time thus lost may be too costly, and we must make every effort to arrive at a correct diagnosis as soon as possible. We must be sure that a pregnant woman whose blood gives false positive reactions for a short period is not stamped as syphilitic with the consequent implications affecting her later pregnancies; on the other hand, we must pay sufficient attention to weak positive reactions and thereby make sure that a syphilitic woman receives such treatment as may enable her to give birth to a healthy child.

The results of the serological testing and of the subsequent treatment of syphilitic women recorded in this study must be regarded as satisfactory. As a final result, 44 syphilitic women gave birth to 35 healthy children. In cases which aborted or gave birth to stillborn children, the mothers had received inadequate treatment or none at all. Even in the four cases in which the syphilis was not detected till the eighth or ninth month of pregnancy, all the infants were saved. It should, however, be noted that these cases occurred after 1946 when penicillin was given.

\section{Conclusions}

The serological control of syphilis in pregnancy practised in Bergen in the period 1944-48, led to the discovery of syphilis in 44 women (8.9 per thousand). As a result of prenatal treatment and of treatment of the new-born, the final result was the birth of 35 healthy infants. This result entirely justified the mass examinations undertaken, and we have every reason for continuing these serological examinations of pregnant women and for the extension of this system to include all pregnant women, whether married or unmarried, primiparae or pluriparae.

\section{Summary}

In 1944 a system of wholesale serological examinations for syphilis during pregnancy was started in Bergen. An account is given of the results obtained by this system in the 5-year period 1944-48.

Altogether 4,961 pregnant women were thus examined. In the same period there were 10,647 confinements in Bergen. About 10,000 women were confined in hospitals where serological tests for syphilis were also undertaken.

These examinations led to the discovery of syphilis in 44 women (i.e. in 8.9 per thousand). As a result of this system, 35 healthy children were born, and have been kept under observation for periods up to three years. 